\title{
Epicrania fugax with backward radiation
}

\author{
Juan A. Pareja · Mónica Álvarez · Teresa Montojo
}

Received: 30 November 2011 / Accepted: 6 December 2011/Published online: 21 December 2011

(C) The Author(s) 2011. This article is published with open access at Springerlink.com

\section{Dear Editor,}

The article by Mulero et al. [1] describing a short series of epicrania fugax (EF) with backward radiation added essential knowledge, and we would like to emphasize the diagnostic relevance of $\mathrm{EF}$ with backward radiation.

The first 20 reported cases of EF [2, 3] had posterior origins of pain with forwards trajectories up to the ipsilateral eye or nostril. Later, Cuadrado et al. [4] described the first two cases with opposite, backward radiation of the pain. Mulero et al. [1] presented a series of EF stemming from anterior regions of the head with backward trajectories up to the occipital area. This observation not only substantiates the clinical picture of EF but also sharpens its nosologic limits with other similar headaches and neuralgias.

Patients with occipital neuralgia have been considered to have pain spreading similar to $\mathrm{EF}$, but were these cases really occipital neuralgia? Mulero et al. [1] provides us with a clarification as all of the patients had the typical features of EF with pain stemming from anterior regions of the head and spreading backward up to the occipital area, and by no means can this movement be considered occipital neuralgia.

The present and previous observations have outlined EF as a distinctive condition characterized by unilateral paroxysms of head pain felt in motion from onset to end, lasting 1-10 s, starting and ending in territories of different cranial nerves. Forward pain stems from the posterior cranial area, tending to reach the ipsilateral eye or nose.

J. A. Pareja $(\square) \cdot$ M. Álvarez · T. Montojo

Department of Neurology, University Hospital

Fundación Alcorcón, Budapest 1, 28922 Alcorcón,

Madrid, Spain

e-mail: japareja@fhalcorcon.es
At the end of the attacks, ipsilateral autonomic signs, such as lacrimation, conjunctival injection, or rhinorrhoea, may occur. Backward pain starts in a frontal or periorbital area tending to reach the ipsilateral occipital region. The origin and ending points are constant in each patient. Although attacks are usually spontaneous, they may occasionally be triggered by touching the area where pain originates, which may remain tender between attacks.

EF emerges as a primary headache with a clear-cut clinical picture that can be differentiated clinically from other headaches and neuralgias.

Conflicts of interest None.

Open Access This article is distributed under the terms of the Creative Commons Attribution License which permits any use, distribution and reproduction in any medium, provided the original author(s) and source are credited.

\section{References}

1. Mulero P, Guerrero AL, Herrero-Velázquez S, Cortijo E, Pedraza M, Peñas ML, Miranda S, Rojo E, Fernández R (2011) Epicrania fugax with backward radiation: clinical characteristics of nine new cases. J Headache Pain 12:535-539

2. Pareja JA, Cuadrado ML, Fernández de las Peñas C, Caminero AB, Nieto C, Sánchez C, Sols M, Porta-Etessam J (2008) Epicrania fugax: an ultrabrief paroxysmal epicranial pain. Cephalalgia 15:257-263

3. Guerrero AL, Cuadrado ML, Porta-Etessam J, García-Ramos R, Gómez-Vicente L, Herrero S, Peñas ML, Fernández R (2010) Epicrania fugax: ten new cases and therapeutic results. Headache 50:451-458

4. Cuadrado ML, Gómez-Vicente L, Porta-Etessam J, Marcos-deVega MA, Parejo-Carbonell B, Matías-Guiu J (2010) Paroxysmal head pain with backward radiation. Will epicrania fugax go in the opposite direction? J Headache Pain 11:75-78 